Article

\title{
Quantum-Sized Zinc Oxide Nanoparticles Synthesised within Mesoporous Silica (SBA-11) by Humid Thermal Decomposition of Zinc Acetate
}

\author{
Tariq Aqeel ${ }^{1, *}$ and Heather F. Greer ${ }^{2}$ (D) \\ 1 Department of Science, College of Basic Education, The Public Authority of Applied Education and \\ Training (PAAET) P.O. Box 23167, Safat 13092, Kuwait \\ 2 Department of Chemistry, University of Cambridge, Cambridge CB2 1EW, UK; hfg24@cam.ac.uk \\ * Correspondence: tm.aqeel@paaet.edu.kw; Tel.: +965-222-1266 (ext. 6269)
}

Received: 10 June 2020; Accepted: 23 June 2020; Published: 26 June 2020

\begin{abstract}
A modified facile method is presented to synthesise quantum-sized zinc oxide nanoparticles within the pores of a mesoporous silica host (SBA-11). This method eliminates the $3 \mathrm{~h}$ alcohol reflux and the basic solution reaction steps of zinc acetate. The mesoporous structure and the $\mathrm{ZnO}$ nanoparticles were analysed by $\mathrm{X}$-ray diffractometry, transmission electron microscopy, energy-dispersive $\mathrm{X}$-ray spectroscopy, X-ray photoelectron spectroscopy, nitrogen sorption analysis and UV-VIS spectroscopy. These tests confirm the synthesis of $\sim 1 \mathrm{~nm}$ sized $\mathrm{ZnO}$ within the pores of SBA-11 and that the porous structure remained intact after $\mathrm{ZnO}$ synthesis.
\end{abstract}

Keywords: quantum; ZnO; nanoparticles; SBA-11; XPS; UV-VIS; XRD

\section{Introduction}

Zinc oxide $(\mathrm{ZnO})$ is a semiconductor material with a band gap of $3.37 \mathrm{eV}$ [1]. It is widely used for its various properties, such as piezoelectric [2], optical [3], capacitors/supercapacitors [4,5], optical-electronic [6], solar [7], sensing [8,9], catalysis [10-12], optical catalysis [13], quantum size effect [14-16], antibacterial/antipathogens [17], and vaccine/tumour prevention [18,19]. Moreover, ZnO nanoparticles reactivity is inversely proportional to its size [20]. One of the methods of controlling the size of any nanoparticles, such as $\mathrm{ZnO}$, is by confinement [21]. Introducing $\mathrm{ZnO}$ precursor into the pores of a mesoporous host [22] can prevent aggregation of the $\mathrm{ZnO}$ particles [23,24], stop them from leaching out as well as increase the surface area and activity of the particles. Moreover, having $\mathrm{ZnO}$ particles in the mesoporous silica host will introduce additional properties for both the guest/host materials and increase its implementation, for example in drug delivery, vaccination [18], photoluminescence [8,22], optical sensing, [25,26], photocatalysis [27], conversion of biomass [28], wound healing [29], hair follicle regeneration [30], tumour prevention [31-33], antibacterial effect [34] and antibiotic adsorption [35]. In addition, both materials silica and $\mathrm{ZnO}$, are nontoxic and relatively cheap to produce [34].

On the other hand, there are many methods of converting zinc oxide precursor such as acetate $\left(\mathrm{Zn}\left(\mathrm{CH}_{3} \mathrm{CO}_{2}\right)_{2} \cdot 2 \mathrm{H}_{2} \mathrm{O}\right)$, into $\mathrm{ZnO}$; for example, by refluxing $\left(\mathrm{Zn}\left(\mathrm{CH}_{3} \mathrm{CO}_{2}\right)_{2} \cdot 2 \mathrm{H}_{2} \mathrm{O}\right)$ in alcohol at $80{ }^{\circ} \mathrm{C}$ for $3 \mathrm{~h}$ and then reacting the product with a basic solution such as $\mathrm{LiOH}$ to form $\mathrm{Zn}(\mathrm{OH})_{\times}$precursor [36] that would be dehydrated (to form metal oxide) to produce $\mathrm{ZnO}$ nanoparticles [37]. Meulenkamp's method [38] eliminates the $3 \mathrm{~h}$ reflux step; however both of these methods employed an alkaline solution for the hydrolysis of $\mathrm{Zn}$ acetate. The use of base tends to dissolve or destroy the porous arrangement of the silica host. Another method is Arii et al.'s method [2], which is performed by the thermal decomposition of zinc acetate dihydrate powder under humid conditions. They reported that the thermal decomposition of zinc acetate dihydrate in a dry inert atmosphere tended to 
sublimate the material at $\sim 180^{\circ} \mathrm{C}$, without forming $\mathrm{ZnO}$. This sublimation stopped when a humid atmosphere is applied during thermal decomposition. Whereas, $\mathrm{ZnO}$ can be prepared by thermal decomposition of zinc acetate dihydrate under humid air at a temperature below $300{ }^{\circ} \mathrm{C}$ [2] according to the following steps:

$$
\begin{gathered}
\mathrm{Zn}\left(\mathrm{CH}_{3} \mathrm{CO}_{2}\right)_{2} \cdot 2 \mathrm{H}_{2} \mathrm{O} \rightarrow \mathrm{Zn}\left(\mathrm{CH}_{3} \mathrm{CO}_{2}\right)_{2} \text { (dehydration: } 50-100{ }^{\circ} \mathrm{C} \text { ) } \\
\mathrm{Zn}\left(\mathrm{CH}_{3} \mathrm{CO}_{2}\right)_{2}+\mathrm{H}_{2} \mathrm{O} \rightarrow \mathrm{ZnO}+2 \mathrm{CH}_{3} \mathrm{COOH}\left(\mathrm{ZnO} \text { formation: } 180-300{ }^{\circ} \mathrm{C}\right. \text { ) } \\
2 \mathrm{CH}_{3} \mathrm{COOH} \rightarrow \mathrm{CH}_{3} \mathrm{COCH}_{3}+\mathrm{CO}_{2}+\mathrm{H}_{2} \mathrm{O} \text { (ethanoic acid decomposition: } \\
\left.180-400{ }^{\circ} \mathrm{C}\right)
\end{gathered}
$$

Moreover, they found that the rate of forming $\mathrm{ZnO}$ is directly proportional to the water partial pressure [2].

Therefore, we created our own method by adapting different steps from these various mentioned methods to introduce $\mathrm{ZnO}$ nanoparticles into a mesoporous silica host. We removed the reflux step, which forms $\mathrm{ZnO}$ in the solution outside the host and terminated the basic hydrolysis reaction step to protect the mesoporous silica host from collapsing to produce quantum sized $\mathrm{ZnO}$ particles confined within the mesoporous silica. We used wet chemistry to dissolve zinc acetate dihydrate in ethanol by heating, then cooling the wet precursor to stop its aggregation [16,37], prior to introducing it to the host. We then applied Arii et al.'s method [2] of humid thermal decomposition of the confined precursor, inside the mesoporous host, to convert the precursor to $\mathrm{ZnO}$ nanoparticles, which is explained in detail in this paper.

\section{Materials and Methods}

\subsection{Preparing $S B A-11$}

SBA-11 was synthesised according to the method reported by Zhao et al. [39]. Simply, $4 \mathrm{~g}$ of polyoxyethylene (10) cetyl ether: [Brij 56: $\mathrm{C}_{16} \mathrm{H}_{33}\left(\mathrm{OCH}_{2} \mathrm{CH}_{2}\right)_{10} \mathrm{OH}$ ] was dissolved in an acidic water mixture of $20 \mathrm{~g}$ deionized $\mathrm{H}_{2} \mathrm{O}+80 \mathrm{~g} \mathrm{HCl}(2 \mathrm{M})$ by stirring at $40{ }^{\circ} \mathrm{C}$. After dissolving the surfactant, it was cooled to room temperature (RT). Subsequently, $8.8 \mathrm{~g}$ of tetraethyl orthosilicate (TEOS) was added to the dissolved surfactant at RT and stirred slowly for $20 \mathrm{~h}$. The product was then filtered, collected and washed several times with deionised water and left to air dry overnight at RT. Finally, the sample powder was calcined at $500{ }^{\circ} \mathrm{C}$ for $6 \mathrm{~h}$ at $2{ }^{\circ} \mathrm{C} \mathrm{min}^{-1}$.

\subsection{Synthesis of $\mathrm{ZnO}$ Particles inside SBA-11}

First, $0.08 \mathrm{~g}$ of zinc acetate was dissolved in $20 \mathrm{~mL}$ methanol $(\mathrm{MeOH})$ at $65{ }^{\circ} \mathrm{C}$ [38] under $\mathrm{N}_{2}$ cover for $30 \mathrm{~min}$. Next, $1 \mathrm{~g} \mathrm{SBA}-11$ was heated at $160{ }^{\circ} \mathrm{C}$ for $2 \mathrm{~h}$ under $\mathrm{N}_{2}$ cover until dehydrated. The two substances were cooled to $0^{\circ} \mathrm{C}$ [16], combined and stirred for $1 \mathrm{~h}$. Stirring was stopped and the product was air dried overnight $(16 \mathrm{~h})$. The product was calcined at $220^{\circ} \mathrm{C}$ under water bubbled air (humid air) for $30 \mathrm{~min}$ then under dry air at $500{ }^{\circ} \mathrm{C}$ for $4 \mathrm{~h}$ at $3{ }^{\circ} \mathrm{C} \mathrm{min}^{-1}$. The powder was washed twice with $\mathrm{MeOH}$ to remove any external $\mathrm{ZnO}$, indicated herein as $\mathrm{ZnO}-\mathrm{SBA}-11$. This produced $2.9 \mathrm{wt} . \% \mathrm{ZnO}$ in SBA-11.

\subsection{Control SBA-11}

One gram of SBA- 11 was heated at $160{ }^{\circ} \mathrm{C}$ for $2 \mathrm{~h}$ under $\mathrm{N}_{2}$ cover until dehydrated. The powder was cooled to $0^{\circ} \mathrm{C}$, then stirred for $1 \mathrm{~h}$ in $20 \mathrm{~mL} \mathrm{MeOH}$. Stirring was stopped and the product was air dried overnight $(16 \mathrm{~h})$. The product was calcined at $220^{\circ} \mathrm{C}$ under water bubbled air (humid air) for $30 \mathrm{~min}$ then under dry air at $500{ }^{\circ} \mathrm{C}$ for $4 \mathrm{~h}$ at $3{ }^{\circ} \mathrm{C} \mathrm{min}^{-1}$ before it was washed twice with $\mathrm{MeOH}$, indicated as control SBA-11.

All chemicals were purchased from Sigma-Aldrich (St. Louis, Missouri, USA) and used as received. 


\section{Results and Discussion}

Figure 1a shows the low-angle powder X-ray diffraction (XRD) patterns of SBA-11 and ZnO-SBA-11. These patterns confirm that both samples are constructed of $P m 3 m$ cubic mesoporous arrangements [39], by the appearance of the main diffraction peaks (indicated with arrows). These peaks did not shift for ZnO-SBA-11 after the synthesis of $\mathrm{ZnO}$ inside the SBA-11 and after the second heat treatment associated with it, confirmed by extending an orange straight line through the (210) peak in both samples to intersect with the $2 \theta$ axis, at a single point of $2.1^{\circ}$. This indicates that the structure is stable and did not distort in the presence of $\mathrm{ZnO}$ particles. Moreover, the intensity decreased in some of the diffraction peaks, indicating that the $\mathrm{ZnO}$ formed in a preferred location. This can be determined by comparing the intensity difference between the (210) and (211) peaks in both samples. The differences are clarified by the aid of purple lines and arrows in Figure 1a with the top line representing the (210) maxima and the lower line indicating the (211) one. The height of h1 of SBA-11 is higher than h2 of ZnO-SBA-11. The wide-angle XRD patterns, Figure 1b, did not show any $\mathrm{ZnO}$ diffraction planes, which confirms that there are no $\mathrm{ZnO}$ particles on the outer surface of SBA-11 and the particles are likely inside the pores [8]. This may also indicate that the $\mathrm{ZnO}$ particles formed are too small to be distinguished from the background noise or to be detected by wide-angle XRD. Moreover, the broad XRD peak at the $2 \theta$ angles from 20 to 30 , also confirms that the silica host (SBA-11) is non crystalline; amorphous walls surrounding an ordered porous arrangement.
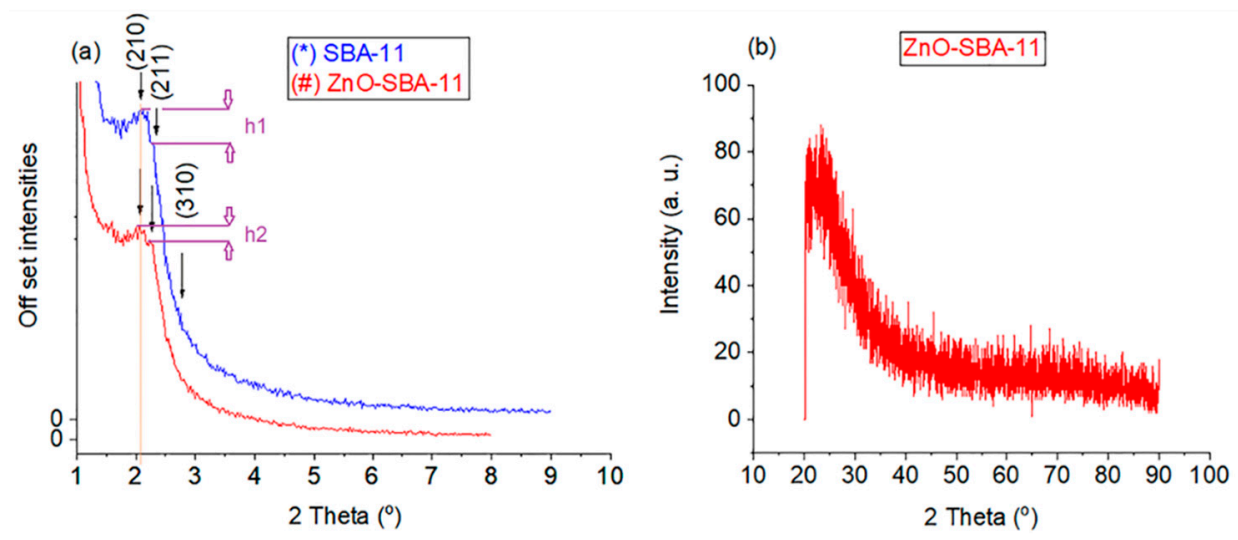

Figure 1. (a) Low-angle XRD patterns of $\left({ }^{*}\right)$ SBA-11 and (\#) ZnO-SBA-11, (b) wide-angle XRD pattern of $\mathrm{ZnO}-\mathrm{SBA}-11$.

Transmission electron microscopy (TEM) characterisation (Figure 2) was performed on the $\mathrm{ZnO}-\mathrm{SBA}-11$ sample to further analyse the structure after the incorporation of $\mathrm{ZnO}$. Figure $2 \mathrm{a}-\mathrm{c}$ is bright-field (BF) TEM images from different locations of the ZnO-SBA-11 sample, which confirm that the sample is porous. These pores extend throughout the entire particles (Figure 2a-c). The average pore diameter measured from these TEM images (Figure 2a-c and Figure S1) is $2 \mathrm{~nm}$. Figure S1, a higher magnification image of Figure 2a clearly displays that some pore channels have sizes of 1.8 to $2.2 \mathrm{~nm}$ as indicated by the yellow lines. Bearing in mind that some of these pores are blocked by the top or bottom layers of the sample, because the electron beam can only penetrate through a few layers and projects the 3D structure into a 2D image. Depending on the view orientation, pore sizes might appear smaller than they actually are, especially for this cubic 3D structure at which the pores are interlocking. A more accurate pore size distribution is obtained from $\mathrm{N}_{2}$ sorption analysis. The darker spots in the BF image, some of which are indicated by red lines and circles in Figure $2 b$ and Figure S1, might indicate the location of $\mathrm{Zn}$ atoms. $\mathrm{Zn}$ has a higher atomic weight than $\mathrm{Si}$, so it will appear darker in the BF TEM images. Moreover, all BF TEM images show that these $\mathrm{ZnO}$ nanoparticles are attached to the internal walls of the pores, indicated by red lines and circles in Figure $2 b$ and Figure S1. This probably occurred during the heat treatment, by losing the organic part of the precursor to form an interaction with the silica framework. This interaction is confirmed in the XPS section with ZnO-SBA-11 having 
higher binding energy values than $\mathrm{ZnO}$ without a silica host. Furthermore, images Figure 2a,c reveal the long-range order of pores (parallel diagonal lines), whilst Figure $2 b$ confirms the interconnected cubic arrangement nature of pores of $\mathrm{ZnO}-\mathrm{SBA}-11$, as confirmed by the XRD data (Figure 1). Figure $2 \mathrm{~d}$ is the dark-field (DF) TEM image of Figure 2c, which indicates the existence of small $\mathrm{ZnO}$ particles and the absence of large aggregates of $\mathrm{ZnO}$ particles. Large $\mathrm{ZnO}$ particles would appear as bright spots in the DF TEM image. DF imaging is more sensitive to $\mathrm{ZnO}$ nanoparticles. This is because $\mathrm{ZnO}$ is crystalline and has a higher atomic number, whereas SBA- 11 consists of amorphous silica with ordered interlocking pores. This is why SBA-11 appears dark in DF images, and only $\mathrm{ZnO}$ particles appears as bright spots. Moreover, we think that we have reached the resolution limits of this TEM instrument, especially in the DF mode, because the $\mathrm{ZnO}$ particles are very small. Figure 2e is the corresponding energy dispersive X-ray spectroscopy (EDX) spectra of ZnO-SBA-11 and Figure $2 \mathrm{f}$ is an enlargement of Figure $2 \mathrm{e}$ to show the relevant peaks clearly. The EDX spectra in Figure 2e,f confirm the composition constituents of ZnO-SBA-11, which are $\mathrm{Si}\left(\mathrm{K}_{\alpha}\right.$ peak at $1.74 \mathrm{keV}$ and $\mathrm{K}_{\beta}$ peak at $\left.1.84 \mathrm{keV}\right), \mathrm{Zn}\left(\mathrm{K}_{\alpha}\right.$ peak at $8.64 \mathrm{keV}, \mathrm{K}_{\beta}$ peak at $9.57 \mathrm{keV}$ and $\mathrm{L}_{\alpha}$ peak at $\left.1.01 \mathrm{keV}\right)$ and $\mathrm{O}\left(\mathrm{K}_{\alpha}\right.$ peak at $\left.0.52 \mathrm{keV}\right)$, whereas $\mathrm{Cu}$ ( $\mathrm{K}_{\alpha}$ peak at $8.05 \mathrm{keV}, \mathrm{K}_{\beta}$ peak at $8.90 \mathrm{keV}$ and $\mathrm{L}_{\alpha}$ peak at $0.93 \mathrm{keV}$ ) is the support grid at which the sample was placed on during the TEM/EDX tests.
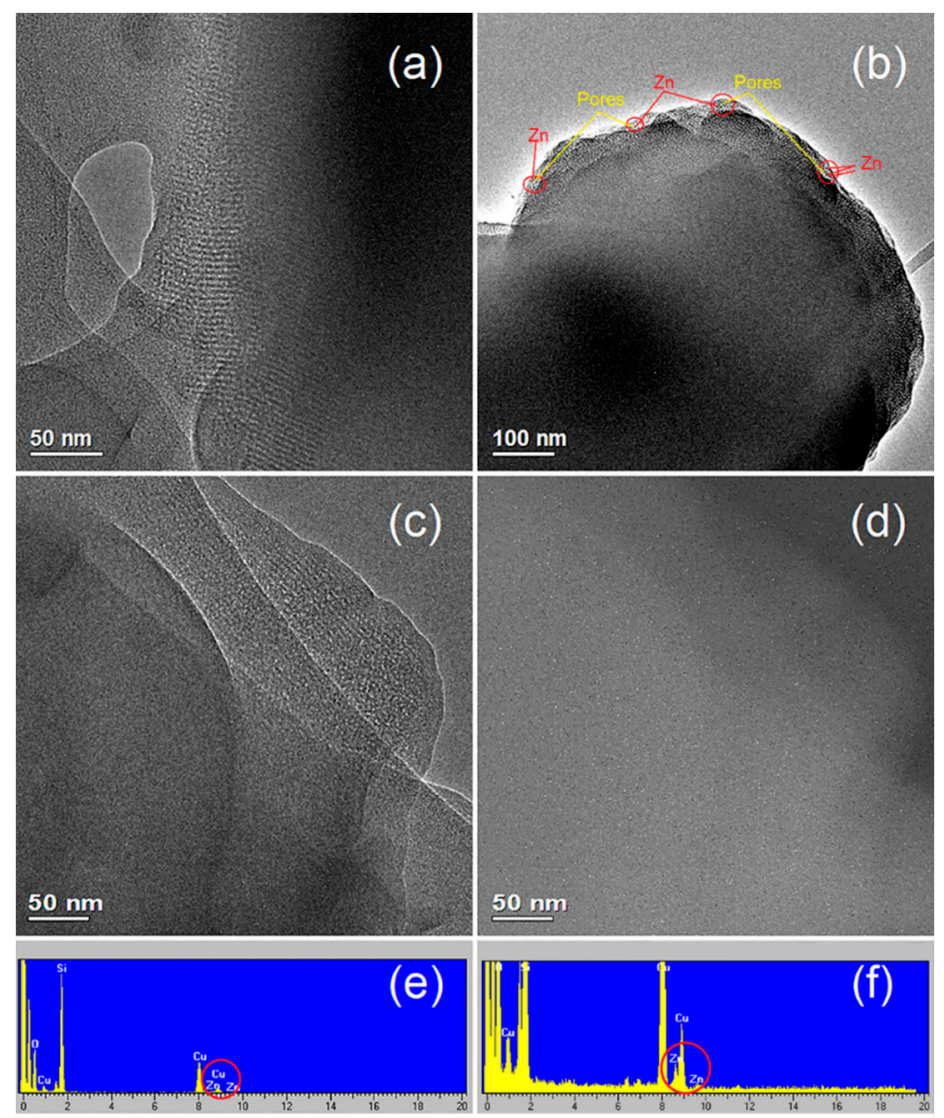

Figure 2. (a-c) Bright-field TEM images from different sections of ZnO-SBA-11, (d) is the dark-field TEM image of (c), (e) is the corresponding energy dispersive X-ray spectroscopy (EDX) of (c,d), and (f) is an enlargement of $(\mathbf{e})$.

X-ray photoelectron spectroscopy (XPS) is conducted on both samples, SBA-11 and ZnO-SBA-11, to study the oxidation states of each constituent of the material's surface, subsurface and to confirm the syntheses of $\mathrm{ZnO}$ particles. Figure 3a,b represents the XPS main peak of $\mathrm{Si}$ at $103.5 \mathrm{eV}$ that has been deconvoluted into two peaks at 103.2 and $104 \pm 0.1 \mathrm{eV}$, representing $2 \mathrm{p}$ orbital splitting into $2 p_{3 / 2}$ and $2 p_{1 / 2}$, respectively $[11,35]$. These peaks are related to $\mathrm{Si}^{4+}$ species in the $\mathrm{SiO}_{2}$ structure. 
Moreover, the oxygen XPS peak at $532.9 \pm 0.2 \mathrm{eV}$ appeared in both samples and corresponds to $\mathrm{O}^{-2}$ in the $\mathrm{SiO}_{2}$ framework (Figure 3c,d) [11,35]. This peak was symmetrical for SBA-11 and asymmetrical for ZnO-SBA-11. This asymmetrical $O$ peak in the latter contains an $\mathrm{O}$ peak at $531.5 \mathrm{eV}$. This peak corresponds to $\mathrm{O}$ in $\mathrm{ZnO}$ in the ZnO-SBA-11 matrix [11,40] and does not appear in SBA-11 (Figure 3d). Furthermore, two designated peaks appeared for the ZnO-SBA-11 sample, Figure 3e, at 1023 [12] and $1046 \mathrm{eV}$, as a result of $2 \mathrm{p}$ orbital splitting of $\mathrm{Zn}^{+2}$ of $\mathrm{ZnO}[11,34,41]$. Moreover, the $\mathrm{Zn} 2 \mathrm{p}$ peaks are slightly higher by $1 \mathrm{eV}$ than that of pure $\mathrm{ZnO}$ without a host, indicating that there is some $\mathrm{Zn}$ interaction with the $\mathrm{Si}$ atoms of the host [8]. This interaction occurs as a result of silicon being more electronegative than zinc, affecting $\mathrm{Zn}$ 's electrons and securely maintaining $\mathrm{ZnO}$ particles in the pores. The difference between these two peaks is $23 \mathrm{eV}$ [34]. Furthermore, by converting the atomic percentages (at. \%) of the constituents to weight percentages (wt.\%) from the XPS data, we calculated $2.4 \mathrm{wt} . \% \mathrm{ZnO}$ in $\mathrm{SiO}_{2}$. These calculations come very close to the experimental calculation that should produce $2.9 \mathrm{wt} . \% \mathrm{ZnO}$ in SBA-11 $\left(\mathrm{SiO}_{2}\right)$. These results further confirm the formation $\mathrm{ZnO}$ in $\mathrm{ZnO}-\mathrm{SBA}-11$.
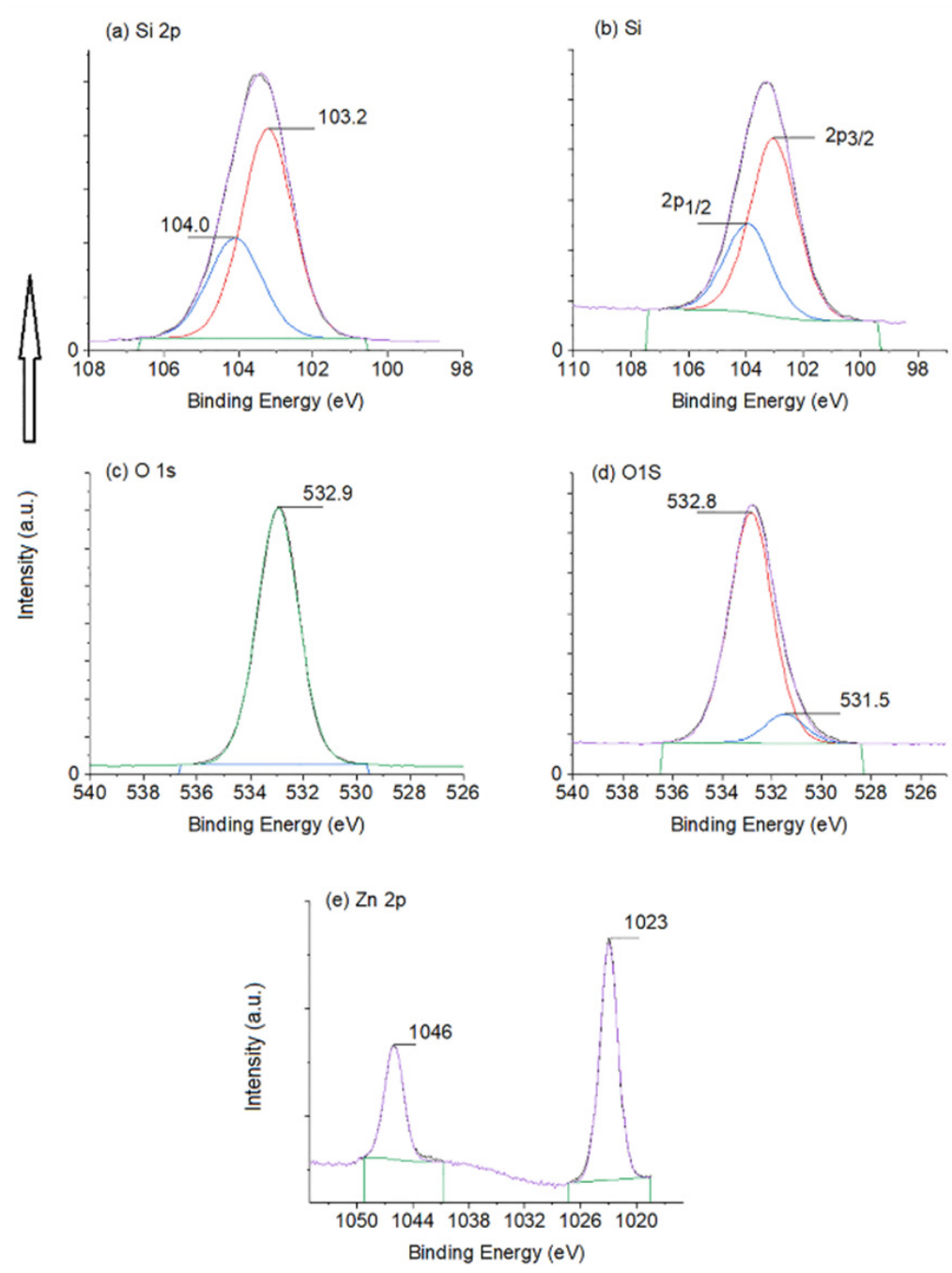

Figure 3. XPS of $(\mathbf{a}, \mathbf{c})$ SBA-11 and (b,d,e) ZnO-SBA-11.

$\mathrm{N}_{2}$ sorption analysis was performed on SBA-11, ZnO-SBA-11 and a control SBA-11 sample to further study if changes occurred in the structure as a result of synthesising $\mathrm{ZnO}$ in SBA-11. The control sample is used to study in detail the effect of humid heat treatment on the structure. Heat treatment in the presence of water or steam is considered as an extreme condition that could destroy the mesoporous silica structure [42-44]. This control sample was prepared using a similar synthetic procedure as $\mathrm{ZnO}-\mathrm{SBA}-11$ but without the $\mathrm{ZnO}$ precusor. All samples produced similar isotherm 
curves (Figure 4a-c). These isotherms are of "IVb type" typical of mesoporous materials, as clasified by The International Union of Pure Applied Chemistry (IUPAC) report 2015 [45]. IVb isotherms are produced by mesoporous materials that possess pore diameters of less than $4 \mathrm{~nm}$ and the cycle is completely reversable (IUPAC report 2015), which is why IVb isotherms do not show any hysteresis curves. A $4 \mathrm{~nm}$ pore size is the minimum critical size to form condensates of liquid-like $\mathrm{N}_{2}$ inside the pores. This formed condensate delays the liquid to vapor transition during the desorption cycle. Mismatch between the speed of forming condensates during adsorption and evaporation during desorption cycles produces hysteresis curves [45]. Moreover, these isotherms produced a saturation plateau after the point of inflection and pore condensation (at relative pressure of $0.3-0.9$, Figure $4 a, b$ ). This indicates that the porous arrangements were intact (also confirmed by low-angle XRD and TEM). Furthermore, all samples produced a narrow pore size distribution between 2 and $3 \mathrm{~nm}$ (Figure $4 \mathrm{~d}-\mathrm{f}$ ), having an average Barrett-Joyner-Halenda (BJH) pore size of $2.15 \pm 0.05 \mathrm{~nm}$ (similar to that obtained from TEM measurements). These pore sizes are in good agreement with the isotherm type and explains why the isotherms did not have hysteresis loops. In addition, the Brunauer-Emmett-Teller (BET) surface area of SBA-11 was $815 \mathrm{~m}^{2} \mathrm{~g}^{-1}$, but after the humid heat treatment, it became $666 \mathrm{~m}^{2} \mathrm{~g}^{-1}$ for the control sample and after synthesising $\mathrm{ZnO}$ in it, it dropped to $620 \mathrm{~m}^{2} \mathrm{~g}^{-1}$ (ZnO-SBA-11). The difference in the surface areas between the control sample and the product (ZnO-SBA-11) is $\sim 7 \%$, indicating the effect of having $\mathrm{ZnO}$ nanoparticles in the pores. The pore volumes were $0.44,0.33$ and $0.32 \mathrm{~cm}^{3}$ $\mathrm{g}^{-1}$, respectively, a drop of $\sim 25 \%$ as a result of humid heat treatment and only $\sim 3 \%$ as a result of $\mathrm{ZnO}$ particles mainly occupying the pores (comparing the controlled sample to the final product). This 3-7\% drop in pore volume or in surface area is an indication of synthesising $\mathrm{ZnO}$ nanoparticles within the pores. If these particles existed on the outer surfaces, they would increase the surface area of the product. We did not observe any significant changes in the pore sizes or any deformation of the structure between the control sample and product. There was a small shrinkage in the average pore sizes $(\sim 0.05 \mathrm{~nm})$ between the starting SBA-11 and ZnO-SBA-11 product. The only differences observed between these samples were in the amount of $\mathrm{N}_{2}$ volume absorbed by all the samples (Figure 4).
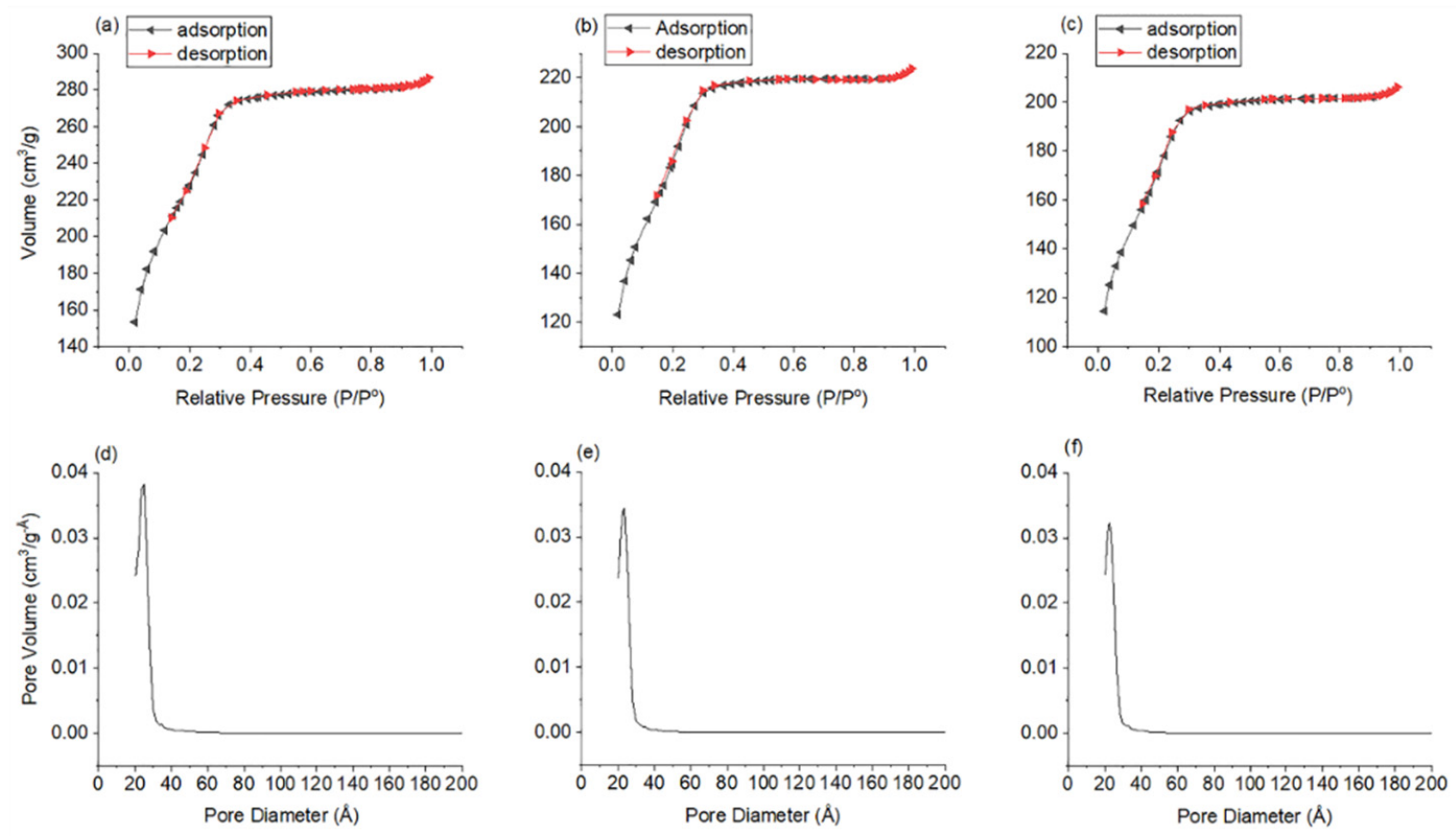

Figure 4. $\mathrm{N}_{2}$ sorption analysis for (a,d) SBA-11, (b,e) control SBA-11 and (c,f) ZnO-SBA-11.

UV-VIS spectroscopy was conducted on ZnO-SBA-11 in the solid state to further confirm the formation of $\mathrm{ZnO}$ particles and to give an indication of their size (SBA-11 was used as a reference sample). The UV peak at $270 \mathrm{~nm}$ indicated by the arrow (Figure 5), confirms the existence of $\mathrm{ZnO}$ 
nanoparticles [15,34] of size $\sim 1 \mathrm{~nm}[16,46]$. It is known that as the size of ZnO particles decreases, the UV peak tends to move towards the blue wavelength region, known as a "blue-shift" as a result of quantum size effect $[16,47]$. This relatively sharp peak indicates a narrow size distribution of small $\mathrm{ZnO}$ particles in the sample. This could explain why we did not observe large bright spots in the dark-field TEM image (Figure 2d). Moreover, the significant drop in the spectra at $350 \mathrm{~nm}$ is the result of the bulb change in the instrument.

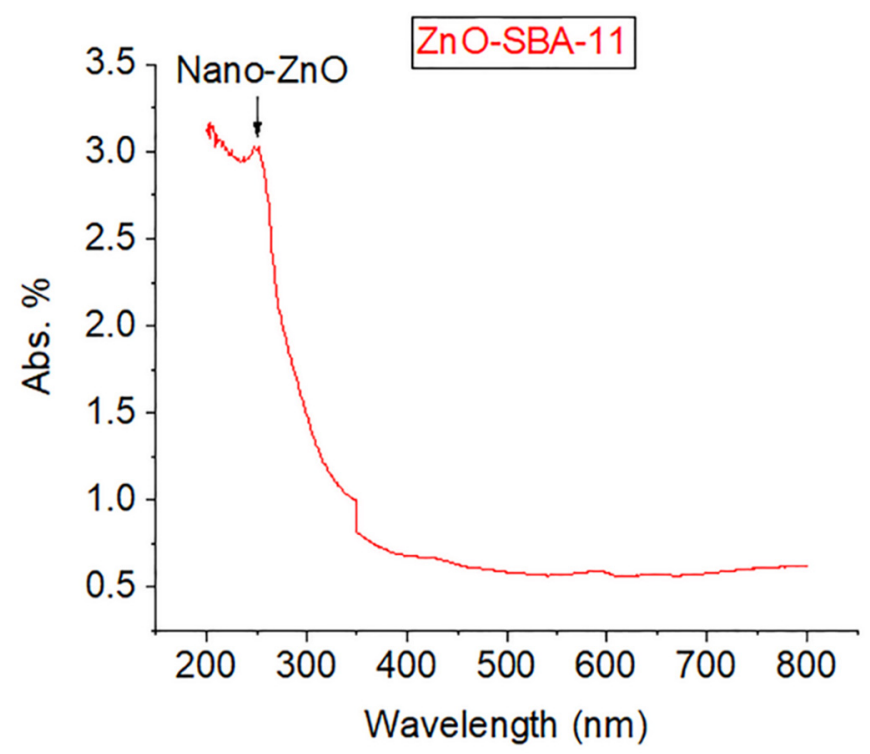

Figure 5. UV-VIS spectroscopy of ZnO-SBA-11 in the solid state.

All these characterisation methods confirm that zinc acetate dihydrade transformed into quantum-sized $\mathrm{ZnO}$ nanoparticles. These particles are imbedded in the internal walls of the SBA-11 pores and formed an interaction with the silica framework without disturbing the porous arrangements of the host. This will ensure that the particles do not leach out from the matrix during wet reactions and will not aggregate in larger groups. Moreover, these $\mathrm{ZnO}$ particles can be readily activated by UV sources, and the product could be employed in many applications and fields that have been presented in the Section 1, especially in wet or optical catalysis. Moreover, this simple ZnO synthesis method could be readily employed to other types of porous hosts and compositions.

\section{Conclusions}

We present a facile method of preparing $\mathrm{ZnO}$ nanoparticles of small sizes, $1 \mathrm{~nm}$, inside the internal walls of the SBA-11 pores without the use of basic exchange reagents or catalysts to convert zinc acetate to $\mathrm{ZnO}$. Moreover, this method does not disturb the pore ordering or alter the mesoporous structure and maintains the high surface area and pore volume of the host material. This signifies that this material can be easily employed in wet, optical catalysis or adsorption reactions. In addition, this facile method could be applied for other porous structures and for different framework constituents.

Supplementary Materials: The following are available online at http://www.mdpi.com/2073-4352/10/6/549/s1, Figure S1. Bright-field TEM image of ZnO-SBA-11. A lower magnification image is shown in Figure 2a.

Author Contributions: T.A. performed the synthesis, $\mathrm{XRD}, \mathrm{N}_{2}$ sorption, UV-VIS and wrote most of this manuscript. Conceptualization, T.A.; formal analysis, T.A.; funding acquisition, T.A.; investigation, T.A. and H.F.G.; methodology, T.A.; project administration, T.A.; resources, T.A.; supervision, T.A.; validation, T.A.; visualization, T.A.; writing-original draft, T.A.; writing-review and editing, T.A. and H.F.G.; H.F.G. performed the TEM/EDX microscopy and wrote the corresponding paragraph in addition to reviewing, editing and proofreading the whole manuscript. All authors have read and agreed to the published version of this manuscript. 
Funding: This project was supported and funded by the Public Authority of Applied Education and Training (PAAET: Project No. BE-15-04 titled “Using Mesoporous Materials to Absorb Sulphur Compounds from Kuwaiti Petroleum Products").

Acknowledgments: This project is performed in collaboration with Duncan Bruce at the University of York $\left(\mathrm{N}_{2}\right.$ sorption and XRD experiments) and Ali Bumajdad and the support of the research administration at Kuwait University by providing the XPS (Project No. GS01/05) and UV-VIS instruments (No. GS01/10) are acknowledged.

Conflicts of Interest: The authors declare that there is no conflict of interest.

\section{References}

1. Munirah; Khan, Z.R.; Aziz, A.; Khan, M.S.; Khandaker, M.U. Influence of zinc concentration on band gap and sub-band gap absorption on $\mathrm{ZnO}$ nanocrystalline thin films sol-gel grown. Mater. Sci. Pol. 2017, 35, 246-253. [CrossRef]

2. Arii, T.; Kishi, A. The effect of humidity on thermal process of zinc acetate. Thermochim. Acta 2003, 400, 175-185. [CrossRef]

3. Schmitt, M. Synthesis and testing of $\mathrm{ZnO}$ nanoparticles for photo-initiation: Experimental observation of two different non-migration initiators for bulk polymerization. Nanoscale 2015, 7, 9532-9544. [CrossRef] [PubMed]

4. Yu, M.; Qiu, W.; Wang, F.; Zhai, T.; Fang, P.; Lu, X.; Tong, Y. Three dimensional architectures: Design, assembly and application in electrochemical capacitors. J. Mater. Chem. A 2015, 3, 15792-15823. [CrossRef]

5. Zhang, G.; Xiao, X.; Li, B.; Gu, P.; Xue, H.; Pang, H. Transition metal oxides with one-dimensional/one-dimensional-analogue nanostructures for advanced supercapacitors. J. Mater. Chem. A 2017, 5, 8155-8186. [CrossRef]

6. Hosono, E.; Fujihara, S.; Kimura, T. Synthesis, structure and photoelectrochemical performance of micro/nano-textured ZnO/eosin Y electrodes. Electrochim. Acta 2004, 49, 2287-2293. [CrossRef]

7. Stroyuk, O.; Raevskaya, A.; Gaponik, N. Solar light harvesting with multinary metal chalcogenide nanocrystals. Chem. Soc. Rev. 2018, 47, 5354-5422. [CrossRef]

8. Jiang, Q.; Wu, Z.Y.; Wang, Y.M.; Cao, Y.; Zhou, C.F.; Zhu, J.H. Fabrication of photoluminescent ZnO/SBA-15 through directly dispersing zinc nitrate into the as-prepared mesoporous silica occluded with template. J. Mater. Chem. 2006, 16, 1536-1542. [CrossRef]

9. Li, Z.; Li, H.; Wu, Z.; Wang, M.; Luo, J.; Torun, H.; Hu, P.; Yang, C.; Grundmann, M.; Liu, X.; et al. Advances in designs and mechanisms of semiconducting metal oxide nanostructures for high-precision gas sensors operated at room temperature. Mater. Horizons 2019, 6, 470-506. [CrossRef]

10. Zhong, J.; Yang, X.; Wu, Z.; Liang, B.; Huang, Y.; Zhang, T. State of the art and perspectives in heterogeneous catalysis of $\mathrm{CO}_{2}$ hydrogenation to methanol. Chem. Soc. Rev. 2020, 49, 1385-1413. [CrossRef] [PubMed]

11. Liu, Y.; Shen, J.; Zhao, L.; Wang, W.; Gong, W.; Zheng, F. Zinc-iron silicate for heterogeneous catalytic ozonation of acrylic acid: Efficiency and mechanism. RSC Adv. 2020, 10, 9146-9154. [CrossRef]

12. Doghri, H.; Baranova, E.A.; Albela, B.; Saïd-Zina, M.; Bonneviot, L. A bio-inspired zinc finger analogue anchored in 2D hexagonal mesoporous silica for room temperature $\mathrm{CO}_{2}$ activation: Via a hydrogenocarbonate route. New J. Chem. 2017, 41, 6795-6809. [CrossRef]

13. Marković, S.; Stojković Simatović, I.; Ahmetović, S.; Veselinović, L.; Stojadinović, S.; Rac, V.; Škapin, S.D.; Bajuk Bogdanović, D.; Janković Častvan, I.; Uskoković, D. Surfactant-assisted microwave processing of ZnO particles: A simple way for designing the surface-to-bulk defect ratio and improving photo(electro)catalytic properties. RSC Adv. 2019, 9, 17165-17178. [CrossRef]

14. Du, Z.; Artemyev, M.; Wang, J.; Tang, J. Performance improvement strategies for quantum dot-sensitized solar cells: A review. J. Mater. Chem. A 2019, 7, 2464-2489. [CrossRef]

15. Tokumoto, M.S.; Briois, V.; Santilli, C.V.; Pulcinelli, S.H. Preparation of ZnO Nanoparticles: Structural Study. J. Sol-Gel Sci. Technol. 2003, 26, 547-551. [CrossRef]

16. Segets, D.; Gradl, J.; Taylor, R.K.; Vassilev, V.; Peukert, W. Analysis of optical absorbance spectra for the determination of $\mathrm{ZnO}$ nanoparticle size distribution, solubility, and surface energy. ACS Nano 2009, 3, 1703-1710. [CrossRef] [PubMed] 
17. Mahamuni, P.P.; Patil, P.M.; Dhanavade, M.J.; Badiger, M.V.; Shadija, P.G.; Lokhande, A.C.; Bohara, R.A. Synthesis and characterization of zinc oxide nanoparticles by using polyol chemistry for their antimicrobial and antibiofilm activity. Biochem. Biophys. Rep. 2019, 17, 71-80. [CrossRef]

18. Li, X.; Wang, X.; Ito, A. Tailoring inorganic nanoadjuvants towards next-generation vaccines. Chem. Soc. Rev. 2018, 47, 4954-4980. [CrossRef]

19. Cai, Q.; Xu, J.; Yang, D.; Dai, Y.; Yang, G.; Zhong, C.; Gai, S.; He, F.; Yang, P. Polypyrrole-coated UCNPs@mSiO $2 @ Z n O$ nanocomposite for combined photodynamic and photothermal therapy. J. Mater. Chem. B 2018, 6, 8148-8162. [CrossRef]

20. Ramakrishna, G.; Ghosh, H.N. Effect of particle size on the reactivity of quantum size ZnO nanoparticles and charge-transfer dynamics with adsorbed catechols. Langmuir 2003, 19, 3006-3012. [CrossRef]

21. Aqeel, T.; Bumajdad, A. facile and direct preparation of ultrastable mesoporous silica with silver nanoclusters: High surface area. ChemistryOpen 2020, 9, 87-92. [CrossRef] [PubMed]

22. Raevskaya, A.E.; Panasiuk, Y.V.; Stroyuk, O.L.; Kuchmiy, S.Y.; Dzhagan, V.M.; Milekhin, A.G.; Yeryukov, N.A.; Sveshnikova, L.A.; Rodyakina, E.E.; Plyusnin, V.F.; et al. Spectral and luminescent properties of ${\mathrm{ZnO}-S i O_{2}}$ core-shell nanoparticles with size-selected ZnO cores. RSC Adv. 2014, 4, 63393-63401. [CrossRef]

23. Tokumoto, M.S.; Pulcinelli, S.H.; Santilli, C.V.; Craievich, A.F. SAXS study of the kinetics of formation of ZnO colloidal suspensions. J. Non. Cryst. Solids 1999, 247, 176-182. [CrossRef]

24. Mikrajuddin; Iskandar, F.; Okuyama, K.; Shi, F.G. Stable photoluminescence of zinc oxide quantum dots in silica nanoparticles matrix prepared by the combined sol-gel and spray drying method. J. Appl. Phys. 2001, 89, 6431-6434. [CrossRef]

25. Zhou, Z.; Lu, K.; Wei, X.; Hao, T.; Xu, Y.; Lv, X.; Zhang, Y. A mesoporous fluorescent sensor based on $\mathrm{ZnO}$ nanorods for the fluorescent detection and selective recognition of tetracycline. RSC Adv. 2016, 6, 71061-71069. [CrossRef]

26. He, J.H.; Ho, S.T.; Wu, T.B.; Chen, L.J.; Wang, Z.L. Electrical and photoelectrical performances of nano-photodiode based on $\mathrm{ZnO}$ nanowires. Chem. Phys. Lett. 2007, 435, 119-122. [CrossRef]

27. Zhou, K.; Ding, Y.; Zhang, L.; Wu, H.; Guo, J. Synthesis of mesoporous $\mathrm{ZnO} / \mathrm{TiO}_{2}-\mathrm{SiO}_{2}$ composite material and its application in photocatalytic adsorption desulfurization without the addition of an extra oxidant. Dalt. Trans. 2020, 49, 1600-1612. [CrossRef]

28. Sudarsanam, P.; Peeters, E.; Makshina, E.V.; Parvulescu, V.I.; Sels, B.F. Advances in porous and nanoscale catalysts for viable biomass conversion. Chem. Soc. Rev. 2019, 48, 2366-2421. [CrossRef]

29. Nethi, S.K.; Das, S.; Patra, C.R.; Mukherjee, S. Recent advances in inorganic nanomaterials for wound-healing applications. Biomater. Sci. 2019, 7, 2652-2674. [CrossRef]

30. Zhang, Y.; Chang, M.; Bao, F.; Xing, M.; Wang, E.; Xu, Q.; Huan, Z.; Guo, F.; Chang, J. Multifunctional Zn doped hollow mesoporous silica/polycaprolactone electrospun membranes with enhanced hair follicle regeneration and antibacterial activity for wound healing. Nanoscale 2019, 11, 6315-6333. [CrossRef]

31. Qian, G.; Wang, X.; Li, X.; Ito, A.; Sogo, Y.; Ye, J. An immuno-potentiating vehicle made of mesoporous silica-zinc oxide micro-rosettes with enhanced doxorubicin loading for combined chemoimmunotherapy. Chem. Commun. 2019, 55, 961-964. [CrossRef] [PubMed]

32. Wen, J.; Yang, K.; Liu, F.; Li, H.; Xu, Y.; Sun, S. Diverse gatekeepers for mesoporous silica nanoparticle based drug delivery systems. Chem. Soc. Rev. 2017, 46, 6024-6045. [CrossRef]

33. Wu, S.; Huang, X.; Du, X. pH- and redox-triggered synergistic controlled release of a ZnO-gated hollow mesoporous silica drug delivery system. J. Mater. Chem. B 2015, 3, 1426-1432. [CrossRef] [PubMed]

34. Qiu, S.; Zhou, H.; Shen, Z.; Hao, L.; Chen, H.; Zhou, X. Synthesis, characterization, and comparison of antibacterial effects and elucidating the mechanism of $\mathrm{ZnO}, \mathrm{CuO}$ and $\mathrm{CuZnO}$ nanoparticles supported on mesoporous silica SBA-3. RSC Adv. 2020, 10, 2767-2785. [CrossRef]

35. Huang, D.; Zhang, Y.; Zhang, J.; Wang, H.; Wang, M.; Wu, C.; Cheng, D.; Chi, Y.; Zhao, Z. The synergetic effect of a structure-engineered mesoporous $\mathrm{SiO}_{2}-\mathrm{ZnO}$ composite for doxycycline adsorption. RSC Adv. 2019, 9, 38772-38782. [CrossRef]

36. Govender, K.; Boyle, D.S.; Kenway, P.B.; O’Brien, P. Understanding the factors that govern the deposition and morphology of thin films of $\mathrm{ZnO}$ from aqueous solution. J. Mater. Chem. 2004, 14, 2575-2591. [CrossRef]

37. Spanhel, L.; Anderson, M.A. Semiconductor clusters in the sol-gel process: Quantized aggregation, gelation, and crystal growth in concentrated ZnO colloids. J. Am. Chem. Soc. 1991, 113, 2826-2833. [CrossRef]

38. Meulenkamp, E.A. Synthesis and growth of ZnO nanowires. J. Phys. Chem. B 1998, 102, 5566-5572. [CrossRef] 
39. Zhao, D.; Huo, Q.; Feng, J.; Chmelka, B.F.; Stucky, G.D. Nonionic triblock and star diblock copolymer and oligomeric sufactant syntheses of highly ordered, hydrothermally stable, mesoporous silica structures. J. Am. Chem. Soc. 1998, 120, 6024-6036. [CrossRef]

40. Wei, X.Q.; Man, B.Y.; Liu, M.; Xue, C.S.; Zhuang, H.Z.; Yang, C. Blue luminescent centers and microstructural evaluation by XPS and Raman in $\mathrm{ZnO}$ thin films annealed in vacuum, $\mathrm{N}_{2}$ and $\mathrm{O}_{2}$. Phys. B Condens. Matter 2007, 388, 145-152. [CrossRef]

41. Tkachenko, O.P.; Klementiev, K.V.; Löffler, E.; Ritzkopf, I.; Schüth, F.; Bandyopadhyay, M.; Grabowski, S.; Gies, H.; Hagen, V.; Muhler, M.; et al. The structure of zinc and copper oxide species hosted in porous siliceous matrices. Phys. Chem. Chem. Phys. 2003, 5, 4325-4334. [CrossRef]

42. Mokaya, R. Improving the stability of mesoporous MCM-41 silica via thicker more highly condensed pore walls. J. Phys. Chem. B 1999, 103, 10204-10208. [CrossRef]

43. Cassiers, K.; Linssen, T.; Mathieu, M.; Benjelloun, M.; Schrijnemakers, K.; Van Der Voort, P.; Cool, P.; Vansant, E.F. A detailed study of thermal, hydrothermal, and mechanical stabilities of a wide range of surfactant assembled mesoporous silicas. Chem. Mater. 2002, 14, 2317-2324. [CrossRef]

44. Linssen, T.; Cassiers, K.; Cool, P.; Vansant, E.F. Mesoporous templated silicates: An overview of their synthesis, catalytic activation and evaluation of the stability. Adv. Colloid Interface Sci. 2003, 103, 121-147. [CrossRef]

45. Thommes, M.; Kaneko, K.; Neimark, A.V.; Olivier, J.P.; Rodriguez-Reinoso, F.; Rouquerol, J.; Sing, K.S.W. Physisorption of gases, with special reference to the evaluation of surface area and pore size distribution (IUPAC Technical Report). Pure Appl. Chem. 2015, 87, 1051-1069. [CrossRef]

46. Zhang, W.H.; Shi, J.L.; Wang, L.Z.; Yan, D.S. Preparation and characterization of ZnO clusters inside mesoporous silica. Chem. Mater. 2000, 12, 1408-1413. [CrossRef]

47. Pesika, N.S.; Stebe, K.J.; Searson, P.C. Relationship between absorbance spectra and particle size distributions for quantum-sized nanocrystals. J. Phys. Chem. B 2003, 107, 10412-10415. [CrossRef]

(C) 2020 by the authors. Licensee MDPI, Basel, Switzerland. This article is an open access article distributed under the terms and conditions of the Creative Commons Attribution (CC BY) license (http://creativecommons.org/licenses/by/4.0/). 